\title{
Pneumolabyrinth: a rare complication of stapes surgery
}

\author{
Patricia S Gomes @i] , ${ }^{1}$ Sergio Caselhos, ${ }^{1}$ Ana Teresa Vide, ${ }^{2}$ Rui Fonseca ${ }^{1}$
}

${ }^{1}$ Otorhinolaryngology, Hospital da Senhora da Oliveira Guimarães, Guimaraes, Portugal ${ }^{2}$ Neuroradiology, Hospital da Senhora da Oliveira Guimarães, Guimaraes, Portugal

Correspondence to Dr Patricia S Gomes: anapatriciasousagomes@gmail. com

Accepted 1 October 2019

Check for updates

(C) BMJ Publishing Group Limited 2019. No commercial re-use. See rights and permissions. Published by BMJ.

To cite: Gomes PS, Caselhos S, Vide AT, et al. BMJ Case Rep 2019:12:e232190. doi:10.1136/bcr-2019232190

\section{SUMMARY}

Pneumolabyrinth is the entrapment of air within the inner ear and is a rare complication of stapes surgery. We report the case of a patient submitted to stapedectomy who, 4 weeks later, suddenly developed right hearing loss, ipsilateral tinnitus and vertigo. On the physical examination, the patient showed no signs of vestibular deficits. Audiometry was compatible with right profound mixed hearing loss and high-resolution CT of the temporal bone revealed the presence of pneumolabyrinth. During exploratory tympanotomy, the prosthesis was found dislodged; the communication between the middle and inner ear was closed with vein graft and a new prosthesis was placed. Following surgery, vestibular symptoms was abolished and the patient experienced great improvement of the hearing thresholds.

\section{BACKGROUND}

Pneumolabyrinth is a rare condition that results from an abnormal communication between the inner and middle ear. In what concerns to acute trauma, stapes surgery is the most common cause of pneumolabyrinth and can present as a late complication of this procedure. ${ }^{1-3}$ Symptoms of presentation include sensorineural hearing loss, tinnitus, aural fullness, vertigo and dizziness. The diagnosis is established by the presence of air within the inner ear in the high-resolution CT (HRCT) of the temporal bone. ${ }^{4}$ We report the case of a pneumolabyrinth affecting the vestibule and lateral semicircular canal that was seen as complication of prosthesis dislocation in a patient who had undergone stapedectomy 4 weeks earlier.

\section{CASE PRESENTATION}

A 47-year-old female patient presented to our emergency department with sudden onset of right hearing loss, ipsilateral high-pitched tinnitus, disequilibrium and rotatory vertigo. Significant in the patient's history was right otosclerosis for which she had undergone a stapedectomy 4 weeks prior to presentation with placement of a Causse fluoroplastic piston $(4.5 \times 0.6 \mathrm{~mm})$ over a tragal perichondrial graft, sealing the oval window.

On physical exam, both tympanic membranes were pearly grey, translucent, intact and mobile. Nystagmus could not be elicited. The head impulse test was negative for a right ear deficit. Romberg and Unterberger-Fukuda tests were normal. The tuning fork tests showed negative Rinne on the right and lateralisation of the sound to the left ear in the Weber test. Hennebert's sign was negative.

\section{INVESTIGATIONS}

Pure-tone audiometry revealed a right profound mixed hearing loss with a pure tone average of $105 \mathrm{~dB}$ hearing level (HL)-figure 1. Speech discrimination was $100 \%$ at $10 \mathrm{~dB} \mathrm{HL}$ on the left and $0 \%$ on the right ear.

The patient underwent HRCT of the temporal bone, which showed the stapes prosthesis in the fossula fenestra vestibuli, a bone defect in the posterior part of the oval window and air trapped in the vestibule, adjacent to the lateral semicircular canal. There was no fluid in the middle ear-figure 2.

\section{TREATMENT}

An initial conservative treatment with highdose intravenous steroids (dexamethasone $8 \mathrm{mg}$, $12 / 12$ hours in the first 5 days, then tapered over 10 days) and antibiotic (ceftriaxone $2 \mathrm{~g}, 12 / 12$ hours) was undertaken. Given the absence of recovery and under the presumptive diagnosis of perilymphatic fistula, the patient was offered an exploratory tympanotomy under general anaesthesia, which she accepted after 3 weeks of reluctance. During the surgery, the stapes prosthesis was found in the fossula fenestra vestibuli, but dislodged from the oval window. After removing the perichondrium graft, which was partially displaced, an active perilymphatic leakage was seen. Vein graft was laid over the oval window and a new Caussepiston $(4.5 \times 0.6 \mathrm{~mm})$ was repositioned in place. In the postoperative period, intravenous corticosteroid (dexamethasone $8 \mathrm{mg} /$ day), antibiotic (ceftriaxone $2 \mathrm{~g}, 12 / 12$ hours), antiemetic (ondansetron $4 \mathrm{mg}$, $8 / 8$ hours) and stool softeners were prescribed. Absolute bed rest was performed during the first 24 hours.

\section{OUTCOME AND FOLLOW-UP}

On the day after the surgery, the patient had no symptoms of vertigo, nausea and did not present spontaneous or elicited nystagmus. The patient was discharged 2 days after the surgery. Postoperative pure tone audiogram performed 3 months later-figure 3-revealed significant improvement of hearing loss with mild persistent right hearing loss (PTA $35 \mathrm{~dB}$ HL and Air-Bone Gap (ABG) $15 \mathrm{~dB}$ $\mathrm{HL})$. The patient is currently on the fifth month after the procedure, has no vestibular complaints, 


\section{Right}

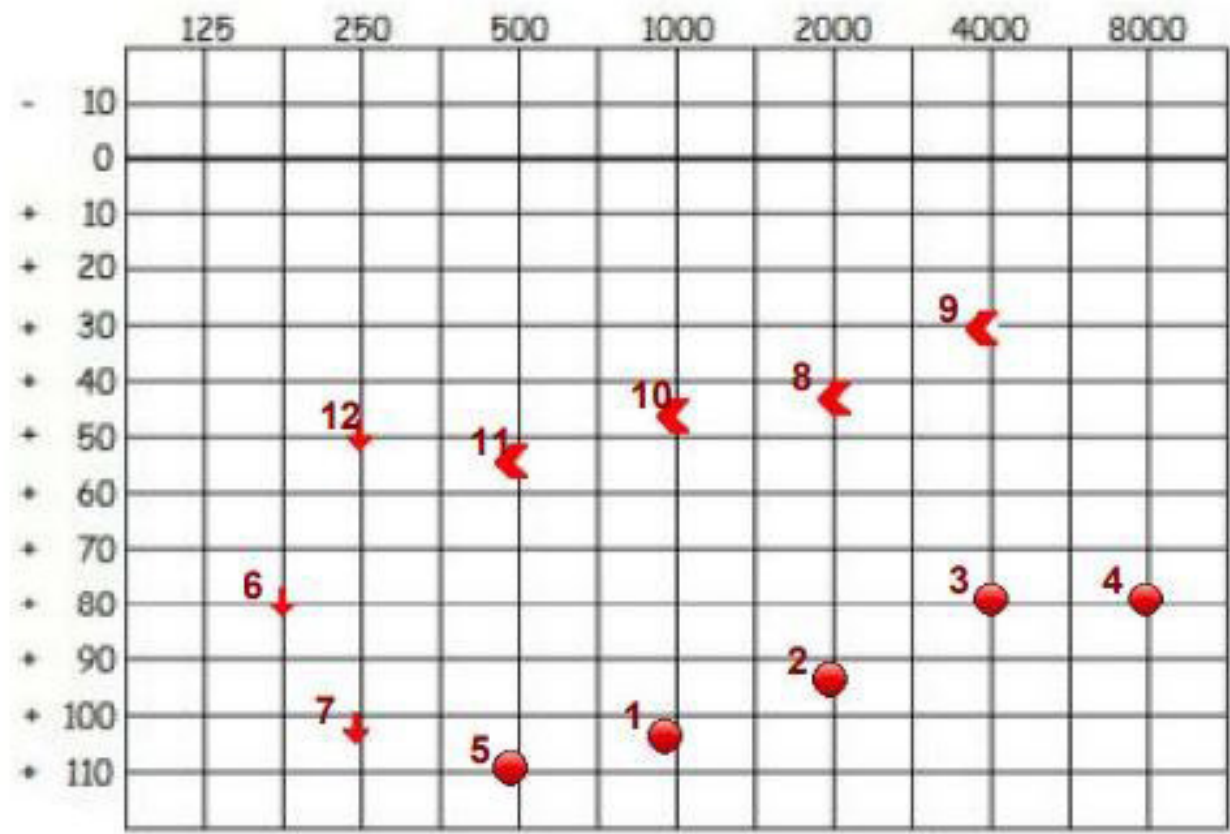

Figure 1 Preoperative audiogram showing right profound mixed hearing loss (Pure Tone Average (PTA) $105 \mathrm{~dB}$ HL).

but refers persistence of the right ear tinnitus, although of lower intensity than before the surgery.

\section{DISCUSSION}

Pneumolabyrinth is a rare condition that can result from a communication between the inner and middle air. There are few cases of pneumolabyrinth published in the literature, most of them diagnosed in patients submitted to primary stapedectomy. ${ }^{3}$ Other causes of pneumolabyrinth include fracture/luxation of footplate, penetrating trauma, temporal bone fractures, barotrauma and cochlear implantation.
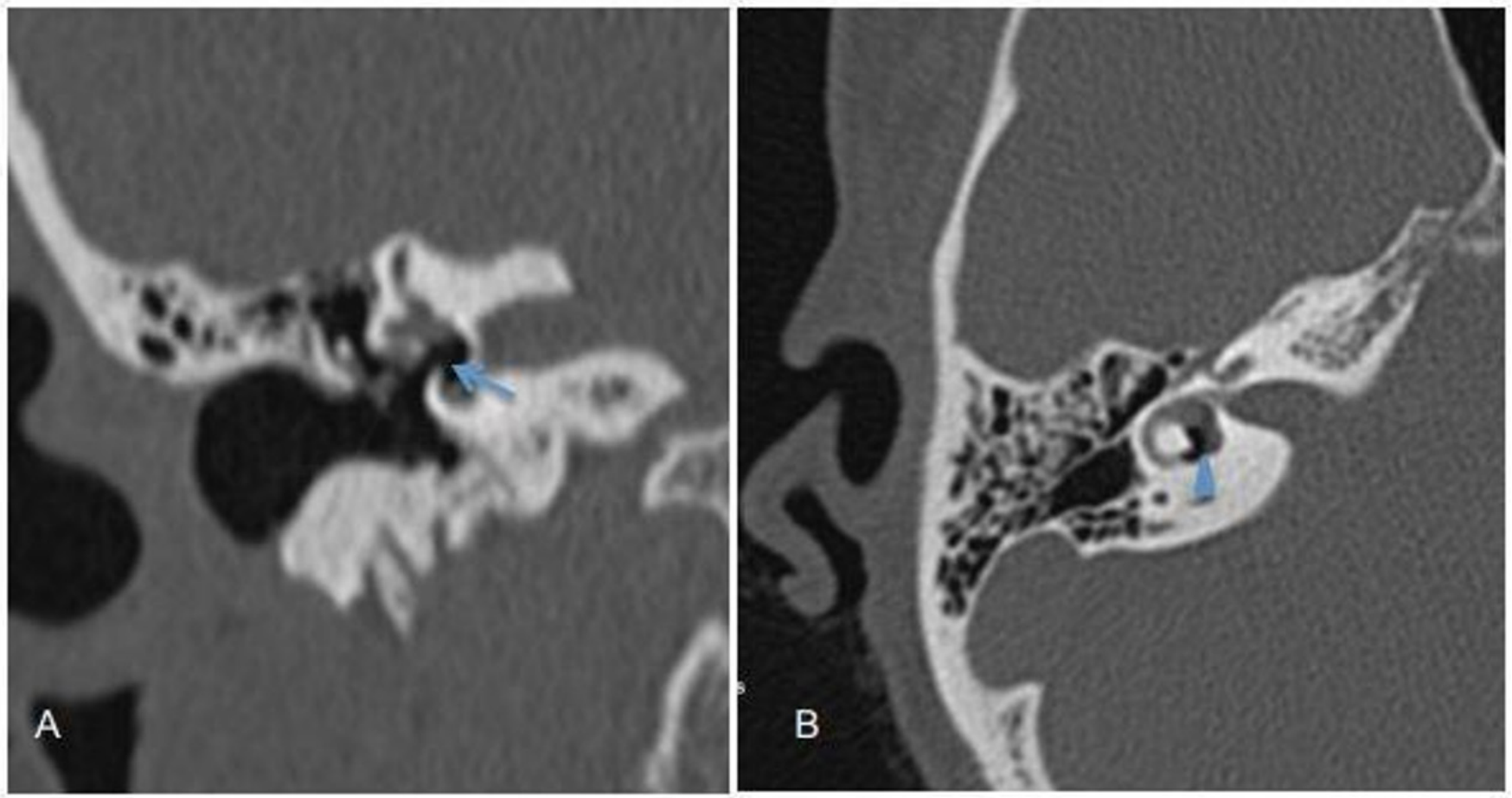

Figure 2 Coronal (A) and axial (B) views of HRCT of temporal bone revealing the presence of pneumolabyrinth characterised by air in the vestible (arrow) and lateral semicircular canal (arrow head). HRCT, high-resolutionCT. 


\section{Right}

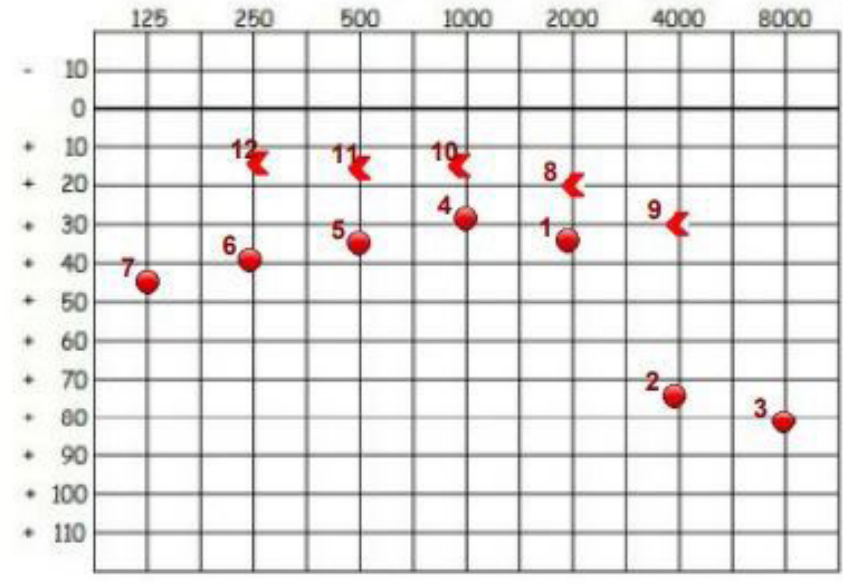

Figure 3 Postoperative audiogram showing right mild conductive hearing loss (PTA $35 \mathrm{~dB} \mathrm{HL}$ ).

When occurring within the first week of stapes surgery, pneumolabyrinth is not considered a complication. ${ }^{5}$ Indeed, the majority of cases described have appeared few weeks or months after the procedure, ${ }^{3}$ although the late onset, several years after stapedectomy, has been described. ${ }^{1-3}$ Conversely, the presence of vertigo, dizziness and sensorineural hearing loss beyond the first week after stapedectomy shall raise the suspicion of perilymphatic fistula. ${ }^{5}$ In this scenario pure-tone audiometry and HRCT scan of the temporal bone shall be undertaken, as the latter can rule out other complications, namely pneumolabyrinth. ${ }^{6}$

Owing to the small number of cases of pneumolabyrinth described in the literature, there is currently no algorithm or consensus regarding the management of this condition. ${ }^{12}$ For patients who develop sudden hearing loss and vestibular symptoms after recent stapes surgery, exploratory tympanotomy is usually advised. ${ }^{1}$ When pneumolabyrinth occurs as a late complication, the decision is not so straightforward. ${ }^{1}$ Nonetheless, in the three cases published in the literature, two patients underwent exploratory tympanotomy with sealing of the defect with fascia, ${ }^{1}$ ear lobule fat $^{3}$ and replacement of the prosthesis and one patient refused surgery, having not experienced worsening of the symptoms. ${ }^{2}$

Regarding outcome measures of surgical exploration of pneumolabyrinth, Tsubota et al found that the prognosis of hearing level was worse than that of the vestibular symptoms. ${ }^{7}$ In addition, they suggested that the period of time until exploratory tympanotomy, the bone conduction hearing level and the presence of stapes lesion were the three main predictors of hearing improvement.

In the present case, the sudden onset of hearing and vestibular symptoms with a history of stapedectomy was highly suggestive of perilymphatic fistula, which was confirmed on HRCT, along with the presence of pneumolabyrinth. Given the finding of air bubbles in the lateral semicircular canal in HRCT, a horizontal nystagmus was expected, but this was not observed. Discrepancy between clinical and radiological findings has been previously reported, ${ }^{13}$ and a possible explanation might be the change of position of air bubbles according to the head position during physical examination and while performing the HRCT. ${ }^{3}$ The decision to perform surgical exploration was made due to the presence of pneumolabyrinth and sensorineural hearing loss in a patient with history of recent stapedectomy. Perilymphatic fistula and prosthesis dislodgment were observed intraoperatively and the communication between the middle and inner ear allowed the entrance of air into the vestibule. Air entrapment in the perilymphatic space is one of the mechanisms involved in hearing loss due to perilymphatic fistula, ${ }^{28}$ and it causes decreased cochlear microphonics, compound action potential and endocochlear potential, rather than strial dysfunction. ${ }^{89}$ Removal of this air is associated with gradual return of the amplitude of cochlear microphonics and action potential, but for scala vestibuli such recovery might not be observed and, accordingly, pneumolabyrinth in the oval window can present with more severe and sometimes irreversible hearing loss. ${ }^{8}$ Our report supports the previous theory as the patient indeed presented profound hearing loss, which significantly improved after surgery, although not returning to baseline levels.

This case reinforces the value of surgical exploration in the management of patients with pneumolabyrinth and sensorineural hearing loss.

\section{Learning points}

Pneumolabyrinth is a rare complication of stapedectomy.

- There is currently no consensus on the management of pneumolabyrinth.

- Treatment options include observation or exploratory tympanotomy with repair of the communication between middle and inner ear.

- Surgical exploration is advisable for patients with pneumolabyrinth and sensorineural hearing loss and/or persistent vertigo.

Contributors PSG takes full responsibility for the integrity of the data presented. $\mathrm{SC}$ and RF contributed to the conception, analysis and interpretation of data. PSG and ATV were responsible for the drafting of the manuscript. All the authors revised the article for important intellectual content and gave their final approval of the version published.

Funding The authors have not declared a specific grant for this research from any funding agency in the public, commercial or not-for-profit sectors.

Competing interests None declared.

Patient consent for publication Obtained.

Provenance and peer review Not commissioned; externally peer reviewed.

ORCID iD

Patricia S Gomes http://orcid.org/0000-0002-1039-2525

\section{REFERENCES}

1 Mandalà M, Colletti L, Carner M, et al. Pneumolabyrinth and positional vertigo after stapedectomy. Auris Nasus Larynx 2011;38:547-50.

2 Scheid SC, Feehery JM, Willcox TO, et al. Pneumolabyrinth: a late complication of stapes surgery. Ear Nose Throat J 2001;80:750-3.

3 Ziade G, Barake R, El Natout T, et al. Late pneumolabyrinth after stapedectomy. Eur Ann Otorhinolaryngol Head Neck Dis 2016;133:361-3.

4 Mafee MF, Valvassori GE, Kumar A, et al. Pneumolabyrinth: a new radiologic sign for fracture of the stapes footplate. Am J Otol 1984;5:374-5.

5 Bajin MD, Mocan Burçe Özgen, Saraç S, et al. Early computed tomography findings of the inner ear after stapes surgery and its clinical correlations. Otol Neurotol 2013;34:639-43.

6 Kosling S, Woldag K, Meister EF, et al. Value of computed tomography in patients with persistent vertigo after stapes surgery. Invest Radiol 1995;30:712-5.

7 Tsubota M, Shojaku H, Watanabe Y. Prognosis of inner ear function in pneumolabyrinth: case report and literature review. Am J Otolaryngol 2009;30:423-6.

8 Kobayashi T, Sakurada T, Ohyama K, et al. Inner ear injury caused by air intrusion to the scala vestibuli of the cochlea. Acta Otolaryngol 1993;113:725-30.

9 Nishioka I, Yanagihara N. Role of air bubbles in the perilymph as a cause of sudden deafness. Am J Otol 1986:7:430-8. 
Copyright 2019 BMJ Publishing Group. All rights reserved. For permission to reuse any of this content visit https://www.bmj.com/company/products-services/rights-and-licensing/permissions/

BMJ Case Report Fellows may re-use this article for personal use and teaching without any further permission.

Become a Fellow of BMJ Case Reports today and you can:

- Submit as many cases as you like

- Enjoy fast sympathetic peer review and rapid publication of accepted articles

Access all the published articles

- Re-use any of the published material for personal use and teaching without further permission

Customer Service

If you have any further queries about your subscription, please contact our customer services team on +44 (0) 2071111105 or via email at support@bmj.com.

Visit casereports.bmj.com for more articles like this and to become a Fellow 